\title{
ANALISIS DAMPAK EKONOMI KEGIATAN WISATA YOUTH CAMP DI TAMAN HUTAN RAYA WAN ABDUL RACHMAN (TAHURA WAR)
}

\author{
(Analysis of the Economic Impact of Tourist Activities in Youth Camp in Taman Hutan Raya \\ Wan Abdul Rachman )
}

\author{
Nur Shafika, Bustanul Arifin, dan Teguh Endaryanto \\ Jurusan Agribisnis, Fakultas Pertanian, Universitas Lampung, Jl. Prof. Dr. Soemantri Brojonegoro No. 1 \\ Bandar Lampung 35141,e-mail : bustanul.arifin@fp.unila.ac.id
}

\begin{abstract}
The main purposes of this research is to find out the characteristic of visitors, local workforces and business owners, the factors that affect the frequency of tourist visits, and to analyze the economic impact caused by the Youth Camp tourism activities. The location for the research is intentionally chosen Youth Camp in Taman Hutan Raya Wan Abdul Rachman. Contributing toward this research consists of 40 visitors, 10 people of local workforce, and 15 business owners. The data for the research were generated in December 2018 to February 2019 and analyzed using methods of descriptive qualitative and descriptive quantitative. The research findings showed that the Youth Camp visitors'ages range between 17-35 years old, originally came from Lampung Province, and on their final year in SMA or equivalent. Majority of them are students employed with income above IDR2,000,000.00, single and no liabilities responsibilities. The frequency of visitors who came to visit was mostly influenced by the distance, age and well known of the tourism place. The value impact obtained from the value of Keynesian Income Multiplier is 5.33, value of Ratio Income Multiplier Type I is 2.70, and value of Ratio Income Multiplier Type II is 3.83.
\end{abstract}

Key words: economic impact, Keynesian multiplier, Youth Camp

\section{PENDAHULUAN}

Pariwisata ikut menumbuhkan ekonomi suatu bangsa. Menurut Malantino (2013), tempat wisata memberikan dampak positif bagi perekonomian masyarakat sekitar. Hal ini dapat dilihat dari peningkatan pendapatan masyarakat, peningkatan lapangan pekerjaan, dan peningkatan sarana infrastruktur. Anggraeni dan Dristanto (2013) menambahkan dampak ekonomi ini terjadi karena adanya perputaran uang antara wisatawan, unit usaha, dan tenaga kerja.

Berdasarkan Neraca Satelit Pariwisata Nasional (Nesparnas) 2017, kontribusi sektor pariwisata terhadap PDB tahun 2017 sebesar 4,11\% (Rp536,77 triliun), serta menyerap 12,74 juta orang atau $10,53 \%$ dari kesempatan kerja di Indonesia. Menurut Mutty (2015), sektor pariwisata membantu mengurangi tingkat pengangguran, menciptakan lapangan pekerjaan bagi masyarakat sekitar objek wisata, seperti pengadaan layanan rumah makan, jasa wisata, pusat oleh-oleh, hingga penginapan. Selain itu dapat meningkatkan pendapatan serta taraf hidup masyarakat. Tidak dapat dipungkiri bahwa industri pariwisata merupakan sektor ekonomi yang cukup vital untuk pertumbuhan ekonomi Indonesia. Salah satu provinsi di Indonesia yang memiliki banyak tempat wisata adalah Provinsi Lampung.
Banyak wisatawan mancanegara maupun nusantara yang setiap tahunnya berkunjung ke Provinsi Lampung. Di Provinsi Lampung banyak terdapat kawasan wisata yang menarik, khususnya wisata alam. Salah satu obyek wisata alam yang patut dipertimbangkan yaitu Taman Hutan Raya. Berdasarkan hasil penelitian Putro (2007), Tahura Wan Abdul Rachman (WAR) memiliki beberapa unit wisata diantaranya panorama alam hutan, pegunungan dan bukit, air terjun ( \pm 20 titik lokasi), goa alam 3 lokasi, sumber air panas 3 titik lokasi, keanekaragaman flora dan fauna, batu lapis, lembah dan sungai, Youth Camp Center. Diantara beberapa unit wisata tersebut, Youth Camp merupakan yang cukup berpotensi, karena merupakan pintu masuk tahura itu sendiri dan pintu gerbang untuk menuju beberapa wisata lainnya seperti air terjun, sungai dan pemandangan alam. Selain itu, Youth Camp semakin ramai dikunjungi dengan dibukanya Pasar Tahura sejak akhir 2017. Menurut Winarno, Sunarminto, dan Avenzora (2011), Youth Camp merupakan potensi ekowisata tahura yang favorable focal point atau titik fokus yang menguntungkan. Putro (2007) menambahkan bahwa Youth Camp memiliki pemandangan alamn yang indah untuk berkemah. Youth Camp juga dijadikan sebagai tempat koleksi tumbuhan seluas lebih kurang 50 ha dan penangkaran satwa burung langka sebanyak 10 jenis burung. 
Kegiatan wisata alam ternyata sangat berdampak positif untuk masyarakat sekitarnya, diantaranya dapat menambah lapangan pekerjaan, memicu kreatifitas masyarakat dalam berkarya, dapat mengenalkan adat dan budaya setempat kepada wisatawan yang datang, serta masyarakat setempat pun memiliki kesempatan untuk mengenal dan berinteraksi dengan wisatawan yang datang dari berbagai suku dan budaya. Berdasarkan uraian di atas, tergambar tentang besarnya potensi wisata yang dimiliki oleh Youth Camp untuk menjadi wisata unggulan bagi masyarakat Lampung. Namun hal tersebut belum tercapai, karena kurangnya pengelolaan yang dilakukan oleh pihak pengelola, sehingga sulit bagi Youth Camp untuk bersaing dengan wisata alam lainnya yang lokasinya berdekatan atau di sekitar Youth Camp.

Untuk lebih menguatkan alasan pengelola untuk segera melakukan pengelolaan secara optimal, butuh alasan yang lebih konkrit yaitu dengan melihat apakah wisata tersebut memiliki dampak ekonomi terhadap masyarakat sekitarnya baik dampak secara langsung, dampak tidak langsung maupun dampak lanjutannya. Kondisi tersebut melatarbelakangi penelitian ini yang berjudul "Analisis Dampak Ekonomi Kegiatan Wisata Youth Camp di Taman Hutan Raya Wan Abdul Rachman" dengan menganalisis karakteristik pengunjung, tenaga kerja lokal dan unit usaha, menganalisis faktor yang mempengaruhi frekuensi kunjungan wisatawan, dan analisis dampak ekonomi yang ditimbulkan oleh kegiatan wisata di sekitar objek wisata tersebut.

\section{METODE PENELITIAN}

Metode penelitian yang digunakan dalam penelitian ini adalah metode survei. Penelitian ini dilakukan di kawasan Tahura Wan Abdul Rachman yaitu Objek Wisata Youth Camp yang terletak di Desa Hurun, Kecamatan Teluk Pandan, Kabupaten Pesawaran, Provinsi Lampung. Pemilihan lokasi dilakukan secara sengaja (purposive), dengan pertimbangan kawasan ini merupakan kawasan wisata yang memiliki banyak potensi yang dapat dikembangkan menjadi salah satu kawasan wisata andalan dan merupakan objek wisata yang lebih menonjol dibanding objek wisata lainnya di kawasan Tahura WAR. Selain memiliki panorama yang masih alami, terdapat berbagai kegiatan wisata lainnya yang dapat dikembangkan di kawasan ini. Youth Camp merupakan destinasi yang cukup menjadi andalan khususnya untuk tempat perkemahan di Provinsi Lampung.
Pengambilan data di lapangan dilakukan pada Desember 2018 hingga Februari 2019.

Metode pengambilan sampel terhadap pengunjung menggunakan cara accidental sampling. Sampel penelitian pengunjung meliputi 40 responden berdasarkan Gujarati (2006) yang menyatakan bahwa tidak peduli distribusi probabilitas apapun yang mendasarinya, rata-rata sampel dari besaran sampel yang terdiri dari sekurang-kurangnya 30 observasi akan mendekati normal.

Metode pengambilan contoh responden pada unit usaha dan tenaga kerja lokal dilakukan dengan bentuk sensus dimana responden untuk unit usaha sebanyak 15 unit usaha dan tenaga kerja lokal sebanyak 10 orang. Menurut Ruslan (2008), jika elemen populasi relatif sedikit dan variabilitas setiap elemennya yang tinggi (heterogen), sensus lebih layak dilakukan, jika penelitian yang dimaksudkan untuk menjelaskan karakteristik setiap elemen dari suatu populasi.

Metode analisis yang digunakan untuk menjawab analisis karakteristik pengunjung, tenaga kerja dan unit usaha adalah analisis deskriptif kualitatif. Analisis deskriptif kualitatif dipilih karena analisis ini dinilai mampu mendeskripsikan dan menggambarkan karakteristik pengunjung, tenaga kerja lokal dan unit usaha yang ada di Youth Camp. Untuk mengidentifikasi karakteristik pengunjung menggunakan indikator atau parameter umur, jenis kelamin, pendidikan terakhir, pendapatan, pekerjaan, jumlah tanggungan, daerah asal, frekuensi kunjungan, sumber informasi, dan status pengunjung (kelompok atau perorangan), alasan kunjungan. Untuk mengidentifikasi karakteristik pelaku usaha, indikator atau parameter yang digunakan adalah umur, jenis kelamin, pendidikan terakhir, pendapatan, jenis usaha yang dijalankan dan lama berusaha. Untuk mengidentifikasi karakteristik tenaga kerja menggunakan indikator atau parameter umur, jenis kelamin, pendidikan terakhir, jenis pekerjaan, lama bekerja, pengalaman kerja dan pendapatan.

Metode analisis untuk mengetahui faktor yang mempengaruhi frekuensi kunjungan adalah metode regresi linier berganda. Faktor-faktor yang mempengaruhinya dilihat berdasarkan faktorfaktor sosial ekonomi yang mempengaruhinya, yaitu :

$$
\begin{aligned}
\mathrm{Y}= & \mathrm{b}_{0}+\mathrm{b}_{1} \mathrm{X}_{1}+\mathrm{b}_{2} \mathrm{X}_{2}+\mathrm{b}_{3} \mathrm{X}_{3}+\mathrm{b}_{4} \mathrm{X}_{4}+\mathrm{b}_{5} \mathrm{X}_{5} \\
& +\mathrm{b}_{6} \mathrm{X}_{6}+\mathrm{b}_{7} \mathrm{X}_{7}+\mathrm{e} \ldots \ldots \ldots \ldots \ldots \ldots \ldots \ldots \ldots \ldots . . .1
\end{aligned}
$$


Keterangan:

$$
\begin{aligned}
& \mathrm{b}_{0} \quad=\text { Konstanta } \\
& \mathrm{b}_{1}-\mathrm{b}_{7}=\text { Koefisien regresi } \\
& \mathrm{Y} \quad=\text { Frekuensi kunjungan ke objek wisata } \\
& \text { (per tahun) } \\
& \mathrm{X}_{1} \quad=\text { Biaya perjalanan individu ke objek } \\
& \text { wisata (Rupiah per kunjungan) } \\
& \mathrm{X}_{2}=\text { Jarak tempuh responden ke objek wisata } \\
& \text { (km) } \\
& \mathrm{X}_{3} \quad=\text { Lama mengetahui keberadaan objek } \\
& \text { wisata (tahun) } \\
& \mathrm{X}_{4}=\text { Pendapatan responden (Rupiah per } \\
& \text { tahun) } \\
& \mathrm{X}_{5} \quad=\text { Umur responden (tahun) } \\
& \mathrm{X}_{6} \quad=\text { Jumlah Tanggungan (orang) } \\
& \mathrm{X}_{7} \quad=\text { Akses ke lokasi wisata } \\
& \text { (mudah }=3 \text {, sedang }=2 \text {, sulit }=1) \\
& \text { e } \quad=\text { Error Term }
\end{aligned}
$$

Metode yang digunakan untuk analisis dampak ekonomi Youth Camp menggunakan multiplier effect atau efek pengganda. Berdasarkan Marine Ecotourism for Atlantic Area (META) (2001) dalam Mutty (2015), dampak ekonomi terhadap masyarakat lokal dapat diukur menggunakan dua tipe pengganda, yaitu :

1. Keynesian Local Income Multiplier Effect, yaitu nilai yang menunjukkan berapa besar pengeluaran pengunjung berpengaruh terhadap peningkatan pendapatan masyarakat lokal.

2. Ratio Income Multiplier, yaitu nilai yang menunjukkan seberapa besar dampak langsung yang dirasakan dari pengeluaran pengunjung berdampak terhadap perekonomian lokal.

Secara sistematis dirumuskan :

Keynesian Income Multiplier $\quad=\frac{\mathrm{D}+\mathrm{N}+\mathrm{U}}{\mathrm{E}}$............(2)

Ratio Income Multiplier, Tipe $\mathrm{I}=\frac{\mathrm{D}+\mathrm{N}}{\mathrm{D}}$.

Ratio Income Multiplier, Tipe II $=\frac{\mathrm{D}+\mathrm{N}+\mathrm{U}}{\mathrm{D}}$

$$
\begin{aligned}
& \text { Keterangan : } \\
& \mathrm{E} \quad=\text { Pengeluaran pengunjung }(\mathrm{Rp}) \\
& \mathrm{D} \quad=\text { Dampak ekonomi langsung }(\mathrm{Rp}) \\
& \mathrm{N} \quad=\text { Dampak ekonomi tidak langsung (Rp) } \\
& \mathrm{U} \quad=\text { Dampak ekonomi lanjutan (Rp) }
\end{aligned}
$$

Dampak ekonomi langsung merupakan pendapatan yang diperoleh oleh unit usaha yang berasal dari pengeluaran wisatawan. Dampak ekonomi tidak langsung diperoleh dari hasil pengeluaran unit usaha berupa biaya operasional seperti biaya sewa, biaya bahan baku, biaya gaji tenaga kerja, biaya transportasi dan biaya pemeliharaan di kawasan wisata. Dampak ekonomi lanjutan (Induced Effect) merupakan dampak ekonomi yang diperoleh berdasarkan pengeluaran yang dikeluarkan oleh tenaga kerja lokal yang berada di kawasan wisata.

Nilai Keynesian Income Multiplier, Ratio Income Multiplier Tipe I, dan Ratio Income Multiplier Tipe II memiliki kriteria sebagai berikut:

1. Apabila nilai tersebut kurang dari atau sama dengan nol $(\leq 0)$, maka lokasi wisata tersebut belum mampu memberikan dampak ekonomi terhadap kegiatan wisatanya.

2. Apabila nilai tersebut diantara angka nol dan satu $(0<\mathrm{x}<1)$, maka lokasi wisata tersebut masih memiliki dampak ekonomi yang rendah.

3. Apabila nilai tersebut lebih besar atau sama dengan satu $(\geq 1)$, maka lokasi wisata tersebut telah mampu memberikan dampak ekonomi terhadap kegiatan wisatanya.

\section{HASIL DAN PEMBAHASAN}

\section{Karakteristik Sosial Ekonomi Pengunjung}

Pengunjung di Youth Camp dengan jenis kelamin perempuan memiliki proporsi lebih besar daripada laki-laki yaitu sebanyak 57,50\%, sedangkan lakilaki hanya sebesar 42,50\%. Menurut Kring dkk. (2007) dalam Fitriani dan Hidayah (2012) sejumlah penelitian menemukan bahwa perempuan tiga kali lebih rentan terhadap depresi dibandingkan laki-laki. Hal ini berlaku baik pada depresi ringan, sedang, maupun berat. Perbedaan gender ini ditemukan pada sejumlah negara, suku bangsa, dan seluruh tahap usia dewasa. Untuk mengurangi depresi, perempuan membutuhkan pengalihan salah satunya dengan berwisata. Hal inilah yang menyebabkan pengunjung perempuan di Youth Camp lebih banyak daripada pengunjung laki-laki.

Berdasarkan umur pengunjung Youth Camp mayoritas berada pada usia 17-25 tahun atau remaja akhir dengan sebanyak $60,00 \%$. Disusul oleh dewasa awal (26-35 tahun) sebanyak 25,00\%. Hasil ini sejalan dengan tujuan Youth Camp yaitu menjadikan wisata ini sebagai bumi perkemahan remaja. Berdasarkan daerah asal, pengunjung dari dalam Provinsi Lampung (selain Desa Hurun) sebanyak 67,50\%, dari Desa Hurun sebanyak $25,00 \%$ dan sisanya sebesar $7,50 \%$ dari luar Provinsi Lampung. Hal ini menunjukkan bahwa Youth Camp cukup populer oleh masyarakat Lampung, namun belum cukup populer oleh masyarakat di luar Provinsi Lampung, sehingga perlu dilakukan promosi lebih baik lagi. Jika dilihat dari karakteristik pendidikan terakhir, 
pengunjung Youth Camp sebanyak 55,00\% adalah SMA/sederajat, disusul dengan perguruan tinggi sebanyak $25,00 \%$ oleh perguruan tinggi, $\mathrm{SMP} /$ sederajat $15,00 \%$ dan sisanya berpendidikan terakhir SD sebanyak 5,00\%. Hal ini menunjukkan bahwa pengunjung Youth Camp berasal dari latar belakang pendidikan yang cukup baik. Hasil ini selaras jika dihubungkan dengan karakteristik pekerjaan, sebanyak $30,00 \%$ pengunjung Youth Camp berstatus mahasiswa dengan kata lain pendidikan terakhir mereka merupakan SMA/ sederajat. Hal ini disebabkan oleh Youth Camp sering dijadikan oleh perkumpulan mahasiswa tempat untuk berkemah, pelatihan, dan lain sebagainya. Jenis pekerjaan kedua terbanyak pengunjung Youth Camp adalah pegawai swasta sebanyak $17,50 \%$ dari total pengunjung. Tingkat pendapatan pengunjung Youth Camp yang paling banyak yaitu pengunjung dengan pendapatan di atas Rp2.000.000,00 sebesar 37,50\%, selanjutnya pengunjung dengan pendapatan berkisar antara $>$ Rp1.000.000,00 hingga Rp2.000.000,00 sebesar $25,00 \%$.

Karakteristik pengunjung di Youth Camp dilihat dari status pernikahan, pengunjung lebih banyak yang belum menikah yaitu $57,50 \%$. Pengunjung yang sudah menikah sebanyak 42,50\%. Hal ini dikarenakan Youth Camp atau bumi perkemahan remaja identik dengan kegiatan anak muda. Jika dihubungkan dengan karakteristik jumlah tanggungan, sebanyak 55,00\% pengunjung Youth Camp tidak memiliki tanggungan, karena memang pengunjung Youth Camp lebih banyak pengunjung yang belum menikah.

\section{Karakteristik Pengunjung dalam Berwisata}

Kebanyakan pengunjung adalah pengunjung yang baru pertama kali datang $(32,50 \%)$ dan pengunjung yang sering datang atau jumlah kunjungannya lebih dari 5 kali $(30,00 \%)$. Sisanya ada yang kunjungan kedua sebanyak $22,00 \%$, kunjungan ketiga $7,50 \%$ dan kunjungan ke empat $7,50 \%$. Pengunjung pertama kali datang kebanyakan karena penasaran dengan cerita teman $(57,50 \%)$. Pengunjung yang datang lebih dari 5 kali umumnya adalah penduduk sekitar Hurun dan mereka tahu wisata ini dengan sendirinya $(25,00 \%)$. Alasan pengunjung datang ke Youth Camp kebanyakan hanya untuk rekreasi di sekitar Youth Camp sebanyak 60,00\%. Biasanya destinasi yang dituju adalah Pasar Tahura. Alasan kedua terbanyak yaitu pengunjung yang datang untuk berkemah sebanyak $17,50 \%$ dan karena air terjun sebagai alasan terbanyak ketiga sebesar $15,00 \%$.

\section{Karakteristik Tenaga kerja}

Berdasarkan hasil penelitian didapatkan bahwa perbandingan tenaga kerja perempuan dan laki-laki yaitu $60,00 \%$ dan $40,00 \%$. Hal ini dikarenakan pekerjaan di Youth Camp tidak terlalu berat dan dapat dilakukan baik oleh perempuan maupun lakilaki. Berdasarkan umur, sebagian besar merupakan remaja akhir atau tenaga kerja dengan rentang umur 17-25 tahun. Tenaga kerja dengan rentang umur ini umumnya merupakan tenaga kerja yang bertanggung jawab mengelola Pasar Tahura. Pasar Tahura merupakan pasar kekinian yang membutuhkan kreativitas dalam menjalankannya, agar sesuai dengan selera masyarakat yang modern dan menarik perhatian pengunjung yang sekarang disebut dengan instragamable, sisanya tenaga kerja dewasa akhir sebanyak $20,00 \%$ dan lansia awal $20,00 \%$. Tenaga kerja pada rentang umur ini merupakan pengelola yang bertanggung jawab memantau keadaan Pasar Tahura dan petugas Youth Camp yang telah bekerja dari lama. Beberapa orang diantaranya petugas Youth Camp, bahkan telah bekerja sejak awal wisata ini didirikan.

Dengan jam kerja rata-rata lebih dari 7 - 10 jam per hari, rata-rata pendapatan tenaga kerja Youth Camp sebesar Rp612.000,00 per bulan. Tenaga kerja Youth Camp khususnya penyelenggara Pasar Tahura hanya bekerja setiap hari hari minggu (empat kali sebulan). Selain itu, hari kerja di Youth Camp tidak menggangu aktivitas utama masingmasing tenaga kerja seperti sekolah ataupun bekerja di instansi lainnya, karena sebagian besar tenaga kerja ini hanya bekerja saat akhir pekan. Penyelenggara Pasar Tahura cukup antusias bekerja di Youth Camp, karena mereka mendapatkan banyak manfaat dengan ikut berpartisipasi mengembangkan wisata ini. Mereka mengenal orang-orang baru, belajar mengelola suatu event, belajar bekerja sama, dan banyak manfaat lainnya yang mungkin dapat dijadikan penelitian selanjutnya membahas dampak non ekonomi dengan adanya Youth Camp ini.

\section{Karakteristik Pemilik Unit Usaha}

Pemilik unit usaha di Youth Camp, sebagian besar merupakan perempuan dengan sebanyak $86,67 \%$ sisanya sebesar $13,33 \%$ merupakan laki-laki. Rentang umur pemilik unit usaha menyebar di remaja akhir, dewasa awal, dewasa akhir, lansia awal, dan lansia akhir. Namun, lansia awal mendapat porsi terbanyak yaitu sebesar 33,33\%, diikuti oleh pemilik unit usaha dewasa awal 
sebanyak 26,67\%, selanjutnya dewasa akhir $20,00 \%$. Sisanya adalah remaja akhir $13,33 \%$ dan lansia akhir 6,67\%. Berdasarkan karakteristik umur, pemilik unit usaha adalah mereka yang tidak lagi muda menunjukkan bahwa Youth Camp memberi peluang usaha bagi masyarakat Youth Camp.

Berdasarkan karakteristik pendidikan terakhir, pemilik unit usaha di Youth Camp berlatar belakang pendidikan SD sama banyak dengan pemilik unit usaha yang pendidikan terakhirnya SMA/sederajat yaitu sebesar 46,67\%. Hal ini menunjukkan bahwa pemilik unit usaha Youth Camp sebagiannya memiliki pendidikan yang cukup tinggi, namun sebagian lagi berpendidikan rendah.

Jika dilihat dari karakteristik lama berusaha, sebagian besar unit usaha bukan pedagang lama karena $73,33 \%$ pemilik unit usaha membuka usahanya pada rentang waktu 1 hingga 5 tahun yang lalu. Unit usaha yang berdiri lebih dari 5 tahun hanya ada satu unit. Hal ini karena dalam beberapa tahun terakhir Youth Camp mengalami penurunan pengunjung, sehingga banyak unit usaha yang tutup. Unit usaha baru mulai berdatangan kembali semenjak dibukanya Pasar Tahura pada akhir tahun 2017. Hal ini tergambar dengan banyaknya unit usaha yang merupakan pedagang Pasar Tahura sebanyak 78,57\%.

\section{Faktor-faktor yang Mempengaruhi Frekuensi Kunjungan di Youth Camp}

Variabel yang dianalisis pada penelitian ini terdiri dari 7 variabel bebas (independent variable) yang diduga berpengaruh terhadap variabel terikat (dependent variable) yaitu frekuensi kunjungan responden pengunjung (Y). Variabel bebas tersebut yaitu biaya perjalanan (X1), jarak tempuh (X2), lama mengetahui keberadaan objek wisata (X3), pendapatan (X4), umur (X5), jumlah tanggungan (X6), dan akses ke lokasi wisata (X7). Rata-rata biaya yang dikeluarkan oleh pengunjung mulai dari rumah hingga kembali ke tempat asal sebesar Rp57.100,00. Jarak yang ditempuh oleh pengunjung dari tempat asal hingga ke lokasi wisata rata-rata $14,27 \mathrm{~km}$ dan pengunjung sudah mengetahui Youth Camp dari lama yaitu sekitar 7 tahun. Tingkat pendapatan pengunjung Youth Camp yang paling banyak yaitu pengunjung dengan pendapatan di atas Rp2.000.000,00 sebanyak $37,50 \%$ selanjutnya pengunjung dengan pendapatan berkisar antara >Rp1.000.000,00 hingga Rp2.000.000,00 sebanyak 25,00\%.
Sebagian besar pengunjung Youth Camp usia 1725 tahun sebanyak 60,00\% dan sebanyak 55,00\% pengunjung Youth Camp tidak memiliki tanggungan. Berdasarkan akses wisata, hanya $5,00 \%$ pengunjung yang menjawab akses ke Youth Camp sulit, sisanya menjawab sedang dan mudah.

Semua variabel diregresi menggunakan regresi linier berganda. Khusus variabel akses ke lokasi wisata (X7) dilakukan transformasi MSI (Methode of Successive Interval), karena datanya masih berbentuk data ordinal. Berdasarkan Tabel 1 diperoleh hasil bahwa jarak tempuh (X2), lama mengetahui keberadaan objek wisata (X3), dan umur (X5) berpengaruh nyata terhadap frekuensi kunjungan pengunjung Youth Camp. Biaya perjalanan berpengaruh tidak nyata terhadap frekuensi kunjungan di Youth Camp dengan taraf kepercayaan di bawah 90,00\%. Hal ini diakibatkan karena biaya perjalanan bisa saja menjadi lebih besar secara mendadak di tempat wisata seperti untuk beli makanan dan pengunjung tidak terlalu memperdulikannya, karena mereka menikmati wisata tersebut.

Variabel jarak tempuh berpengaruh nyata terhadap frekuensi kunjungan dengan taraf kepercayaan 95,00\%. Jika jarak tempuh naik satu km, maka akan menurunkan frekuensi kunjungan sebesar 0,61 kali. Lama mengetahui keberadaan objek wisata yang berpengaruh secara signifikan terhadap frekuensi kunjungan di Youth Camp. Berdasarkan hasil analisis regresi, variabel lama mengetahui keberadaan objek wisata ini memiliki koefisien sebesar 0,76 artinya semakin lama seseorang mengetahui Youth Camp, maka akan meningkatkan frekuensi kunjungan ke objek wisata ini.

Tabel 1. Hasil analisis regresi faktor-faktor yang mempengaruhi frekuensi kunjungan di Youth Camp setelah ditransformasi

\begin{tabular}{llrl}
\hline No Variabel (X) & \multicolumn{1}{c}{ B } & \multicolumn{1}{c}{ t-hit } & Sig \\
\hline Constant & 23,623 & 2,876 & 0,007 \\
1 Biaya (X1) & $-9,634$ & $-0,226$ & 0,821 \\
2 Jarak (X2) & $-0,613^{* * *}$ & $-3,157$ & 0,003 \\
3 Lama mengetahui (X3) & $0,758^{* * *}$ & 3,333 & 0,002 \\
4 Pendapatan (X4) & 9,730 & 1,153 & 0,257 \\
5 Umur (X5) & $-0,413^{* *}$ & $-2,155$ & 0,038 \\
6 Jumlah tanggungan & & & \\
$\quad$ (X6) & $-0,410$ & $-0,309$ & 0,759 \\
7 Akses (X7) & $-0,681$ & $-0,380$ & 0,705 \\
\hline
\end{tabular}

Keterangan : *** Taraf kepercayaan $99 \%$

** Taraf kepercayaan $95 \%$

* Taraf kepercayaan $90 \%$ 
Variabel pendapatan berpengaruh tidak nyata terhadap frekuensi kunjungan dengan taraf kepercayaan di bawah 90,00\%. Hal ini disebabkan karena wisata Youth Camp bukanlah wisata yang membutuhkan banyak pengeluaran dan tiket masuk tergolong sangat murah, sehingga wisata ini dapat dinikmati oleh siapapun, tidak terpengaruh oleh seberapa besar pendapatan seseorang tersebut. Variabel umur berpengaruh nyata terhadap frekuensi kunjungan di Youth Camp dengan taraf kepercayaan 95,00\% dengan koefisien sebesar 0,413 yang artinya semakin bertambahnya umur seseorang satu tahun akan menurunkan frekuensi kunjungan ke Youth Camp sebesar 0,41 satuan.

Jumlah tanggungan berpengaruh tidak nyata terhadap frekuensi kunjungan di Youth Camp dengan taraf kepercayaan di bawah 90,00\%. Variabel jumlah tanggungan akan berhubungan dengan finansial seseorang, karena semakin banyak tanggungan, maka pengeluarannya akan semakin besar. Selaras dengan tidak berpengaruhnya variabel pendapatan, sama halnya dengan variabel jumlah tanggungan ini. Youth Camp merupakan wisata alam yang murah, sehingga tidak terlalu pengaruh oleh jumlah tanggungan pengunjung tersebut. Akses ke lokasi wisata berpengaruh tidak nyata terhadap frekuensi kunjungan ke Youth Camp dengan taraf kepercayaan kurang dari 90,00\%. Variabel akses ke lokasi wisata seringkali diabaikan oleh pengunjung, jika tempat wisata tersebut benarbenar menjanjikan dan sesuai dengan selera masing-masing individu.

\section{Dampak Ekonomi Langsung}

Pengunjung yang datang ke Youth Camp akan melakukan banyak aktivitas, diantaranya bermain di air terjun, rekreasi di sekitar Youth Camp, berkemah, berbelanja makanan baik di kantin Youth Camp maupun Pasar Tahura dan menggunakan toilet. Penerimaan yang diterima oleh Pasar Tahura, kantin Youth Camp dan WC umum dikurang dengan biaya-biaya dihitung sebagai dampak langsung. Pengeluaran yang dilakukan oleh pengunjung dibedakan menjadi pengeluaran di luar kawasan wisata dan pengeluaran di lokasi wisata. Pengeluaran pengunjung yang akan digunakan dalam perhitungan nilai pengganda (multiplier effect) adalah pengeluaran rata-rata pengunjung dilokasi wisata dikali dengan jumlah pengunjung dalam satu bulan. Berdasarkan hasil perhitungan diperoleh pengeluaran pengunjung (E) sebesar Rp6.834.187,50. Dampak ekonomi langsung dari kegiatan wisata merupakan pendapatan yang diperoleh oleh unit usaha (kantin Youth Camp, Pasar Tahura, dan WC umum) yang berasal dari pengeluaran wisatawan. Berdasarkan Tabel 2, total pengeluaran pengunjung di lokasi wisata adalah Rp9.506.000,00 per bulan.

Unit usaha yang terdapat di Youth Camp yaitu kantin Youth Camp, Pasar Tahura, dan WC umum. Pendapatan tiap unit usaha berbeda-beda. Dampak ekonomi langsung didapat dari hasil mengalikan jumlah populasi unit usaha yang ada dengan ratarata pendapatan unit usaha per bulan di Youth Camp. Nilai dampak ekonomi terbesar diperoleh pedagang Pasar Tahura yaitu sebesar Rp5.286.000,00 per bulan, karena populasinya lebih banyak. Unit usaha WC umum memperoleh dampak ekonomi langsung paling sedikit yaitu sebesar Rp480.000,00 per bulan, karena hanya ada satu unit dan bersaing dengan WC umum yang disediakan Youth Camp. Unit usahan kantin Youth Camp menerima dampak ekonomi langsung sebesar Rp3.740.000,00 per bulan, sehingga di dapat total dampak ekonomi langsung dari ketiga unit usaha sebesar Rp9.451.000,00 per bulan.

\section{Dampak Ekonomi Tidak Langsung}

Dampak ekonomi tidak langsung diperoleh dari hasil pengeluaran unit usaha berupa biaya operasional seperti biaya sewa, biaya bahan baku, biaya gaji tenaga kerja, biaya transportasi dan biaya pemeliharaan di kawasan Youth Camp. Keberadaan Youth Camp juga menyerap tenaga kerja lokal yang ada di sekitar, sehingga menimbulkan dampak tidak langsung. Pengeluaran unit usaha dilakukan di dalam kawasan wisata dan di luar kawasan wisata. Biaya yang dikeluarkan di luar kawasan wisata adalah yaitu biaya transportasi. Dampak ekonomi tidak langsung dilihat dengan menjumlahkan rata-rata pengeluaran unit usaha di kawasan Youth Camp dan total pendapatan tenaga kerja. Perhitungan mengenai dampak tidak langsung tersaji pada Tabel 3.

Tabel 2. Dampak ekonomi langsung di Youth Camp

\begin{tabular}{lrcr}
\hline \multicolumn{1}{|c}{ Unit usaha } & $\begin{array}{c}\text { Jumlah } \\
\text { (a) }\end{array}$ & $\begin{array}{c}\text { Rata-rata } \\
\text { pendapatan } \\
\text { (Rp/bln) (b) }\end{array}$ & $\begin{array}{c}\text { Dampak ekonomi } \\
\text { langsung (Rp/bln) } \\
\text { (c= a x b) }\end{array}$ \\
\hline $\begin{array}{l}\text { Kantin Youth } \\
\text { Camp }\end{array}$ & 3 & $1.246 .666,67$ & $3.740 .000,00$ \\
$\begin{array}{l}\text { Pedagang } \\
\text { Pasar Tahura }\end{array}$ & 11 & $480.545,45$ & $5.286 .000,00$ \\
WC umum & 1 & $480.000,00$ & $480.000,00$ \\
\hline \multicolumn{4}{l}{ Total } \\
Sumber : data primer diolah $(2019)$
\end{tabular}


Tabel 3. Dampak ekonomi tidak langsung di Youth Camp

\begin{tabular}{|c|c|c|c|c|c|}
\hline Jenis Usaha & $\begin{array}{c}\text { Jumlah } \\
\text { tenaga } \\
\text { kerja } \\
\text { (a) } \\
\end{array}$ & $\begin{array}{c}\text { Gaji } \\
\text { tenaga } \\
\text { kerja }(\mathrm{Rp}) \\
\text { (b) }\end{array}$ & $\begin{array}{c}\text { Total } \\
\text { gaji tenaga } \\
\text { kerja }(\mathrm{Rp}) \\
(\mathrm{c}=\mathrm{a} \text { (b) }\end{array}$ & $\begin{array}{l}\text { Pengeluaran unit usaha } \\
\text { di kawasan wisata } \\
\text { (di luar gaji tenaga } \\
\text { kerja) (Rp) (d) } \\
\end{array}$ & $\begin{array}{c}\text { Dampak } \\
\text { ekonomi tidak } \\
\text { langsung }(\mathrm{Rp}) \\
(\mathrm{e}=\mathrm{c}+\mathrm{d}) \\
\end{array}$ \\
\hline \multicolumn{6}{|l|}{ Unit Usaha } \\
\hline Kantin Youth Camp & 5 & $200.000,00$ & $1.000 .000,00$ & $1.980 .000,00$ & 000,00 \\
\hline Pedagang Pasar Tahura & 15 & $50.909,09$ & $763.636,36$ & $6.160 .000,00$ & $6.923 .636,36$ \\
\hline WC umum & 0 & 0,00 & 0,00 & $100.000,00$ & $100.000,00$ \\
\hline \multicolumn{6}{|l|}{ Tenaga Kerja } \\
\hline Penyelenggara Pasar Tahura & 6 & $153.333,33$ & $920.000,00$ & 0,00 & $920.000,00$ \\
\hline Petugas Youth Camp & 4 & $1.300 .000,00$ & $5.200 .000,00$ & 0,00 & $5.200 .000,00$ \\
\hline Total & & & & & $16.123 .636,36$ \\
\hline
\end{tabular}

Sumber : data primer diolah (2019)

Dampak ekonomi tidak langsung di Youth Camp terbesar berasal dari pedagang Pasar Tahura yaitu Rp6.923.636,36. Besarnya dampak ekonomi yang disumbangkan oleh pedagang Pasar Tahura, karena besarnya biaya yang mereka keluarkan di sekitar Youth Camp, diantaranya biaya bahan baku, sewa, tenaga kerja, dan kebersihan. Selain itu karena pedagang Pasar Tahura memiliki unit yang paling banyak dibandingkan unit usaha yang lain.

\section{Dampak Ekonomi Lanjutan}

Dampak ekonomi lanjutan (Induced Effect) merupakan dampak ekonomi yang diperoleh berdasarkan pengeluaran yang dikeluarkan oleh tenaga kerja lokal yang berada di kawasan wisata. Jenis pengeluaran yang dikeluarkan tenaga kerja lokal adalah untuk biaya konsumsi, biaya sekolah anak, biaya listrik dan biaya kebutuhan sehari-hari. Pengeluaran tenaga kerja di kawasan wisata dapat memberikan dampak positif terhadap perekonomian masyarakat sekitar. Persentase pengeluaran tenaga kerja terjadi di kawasan Youth Camp sangat tinggi yaitu $99,00 \%$ untuk penyelenggara Pasar Tahura dan 95,00\% untuk petugas Youth Camp. Dampak ekonomi lanjutan diperoleh dengan cara jumlah tenaga kerja lokal dikali total rata-rata pengeluaran tenaga kerja dan dikali persentase pengeluaran di kawasan wisata. Berdasarkan Tabel 4 diperoleh dampak ekonomi lanjutan di Youth Camp sebesar Rp10.791.312,53.

Tabel 4. Dampak ekonomi lanjutan di Youth Camp

\begin{tabular}{|c|c|c|c|c|}
\hline Tenaga kerja & $\begin{array}{l}\text { Jumlah } \\
\text { tenaga } \\
\text { kerja (a) }\end{array}$ & $\begin{array}{c}\text { Total rata-rata } \\
\text { pengeluaran } \\
\text { tenaga kerja }(\mathrm{Rp}) \\
\text { (b) } \\
\end{array}$ & $\begin{array}{l}\text { Persentase } \\
\quad \text { (c) }\end{array}$ & $\begin{array}{c}\text { Dampak } \\
\text { ekonomi } \\
\text { lanjutan }(\mathrm{Rp}) \\
(\mathrm{d}=\mathrm{axbxc}) \\
\end{array}$ \\
\hline $\begin{array}{l}\text { Penyelenggara } \\
\text { Pasar Tahura }\end{array}$ & 6 & $945.500,00$ & 0,99 & $5.620 .000,00$ \\
\hline $\begin{array}{l}\text { Petugas Youth } \\
\text { Camp } \\
\end{array}$ & 4 & $1.357 .815,38$ & 0,95 & $5.171 .312,53$ \\
\hline Total & & & & $10.791 .312,53$ \\
\hline
\end{tabular}

\section{Nilai Efek Pengganda (Multiplier Effect)}

Nilai efek penggandaan (Multiplier) dapat digunakan untuk mengukur seberapa besar dampak ekonomi yang timbul dari adanya pengeluaran pengunjung yang dapat digunakan selama mereka melakukan kegiatan rekreasi. Terdapat tiga ukuran dalam mengukur dampak ekonomi wisata di tingkat lokal, yaitu Keynesian Local Income Multiplier merupakan nilai yang menunjukkan pengaruh dari pengeluaran pengunjung terhadap pendapatan masyarakat lokal, Ratio Income Multiplier tipe I, yaitu nilai yang diperoleh dari dampak langsung dari pengeluaran pengunjung, dan Ratio Income Multiplier tipe II, yaitu nilai yang diperoleh dari dampak lanjutan. Hasil perhitungan efek penggandaan (multiplier) dapat dilihat pada Tabel 5 .

Berdasarkan Tabel 5 nilai Keynesian Income Multiplier sebesar 5,33 artinya setiap peningkatan Rp10.000,00 pengeluaran wisatawan akan berdampak terhadap ekonomi lokal sebesar Rp53.300,00. Nilai Ratio Income Multiplier Tipe I sebesar 2,70 artinya setiap peningkatan Rp10.000,00 pada penerimaan unit usaha akan mengakibatkan peningkatan sebesar Rp27.000,00 terhadap pendapatan pemilik unit usaha dan tenaga kerja. Nilai Ratio Income Multiplier Tipe II sebesar 3,83 artinya setiap kenaikan Rp10.000,00 pada penerimaan pemilik unit usaha, maka akan mengakibatkan peningkatan sebesar Rp38.300,00 pada pendapatan pemilik unit usaha, pendapatan tenaga kerja, dan pengeluaran konsumsi tenaga kerja dalam putaran perekonomian lokal di kalangan masyarakat sekitar. Perhitungan nilai efek pengganda menunjukkan bahwa ketiga nilai tersebut di atas satu yang artinya wisata Youth Camp memberi dampak terhadap perekonomian masyarakat sekitar. 
Tabel 5. Nilai pengganda (multiplier effect) dari arus uang yang terjadi youth camp

\begin{tabular}{lcc}
\hline \multicolumn{1}{c}{ Multiplier } & Nilai \\
\hline Keynesian Income Multiplier & $(\mathrm{D}+\mathrm{N}+\mathrm{U}) / \mathrm{E}$ & 5,33 \\
Ratio Income Multiplier Tipe 1 & $(\mathrm{D}+\mathrm{N}) / \mathrm{D}$ & 2,70 \\
Ratio Income Multiplier Tipe 2 & $(\mathrm{D}+\mathrm{N}+\mathrm{U}) / \mathrm{D}$ & 3,83 \\
\hline \multicolumn{2}{l}{ Sumber : data primer diolah (2019) } &
\end{tabular}

E : Pengeluaran pengunjung $\quad$ : Rp6.834.187,50

D: Pendapatan lokal yang diperoleh secara langsung : Rp9.506.000,00

$\mathrm{N}$ : Pendapatan lokal yang diperoleh secara tidak langsung : :Rp16.123.636,36

U: Pendapatan lokal yang diperoleh secara induced dari E

: Rp10.791.312,53

\section{KESIMPULAN}

Pengunjung wisata Youth Camp mayoritas berada pada rentang umur 17 - 25 tahun yang berasal dari sekitar Hurun dan Provinsi Lampung dengan pendidikan terakhir SMA/sederajat dan bertatus sebagai mahasiswa ataupun sudah bekerja sebagai pegawai swasta. Pendapatan pengunjung sebagian besar lebih Rp1.000.000,00 per bulan. Pengunjung yang belum menikah lebih banyak dan sebagian besar belum memiliki tanggungan dan baru pertama kali. Pengunjung dapat informasi dari teman dan datang dengan kelompok kecil dengan tujuan rekreasi.

Tenaga kerja di Youth Camp sebagian besar masih remaja akhir dengan tingkat pendidikan terakhir $\mathrm{SMP} /$ sederajat. Sebagian besar tenaga kerja bekerja 7-10 jam per hari dengan rata-rata pendapatan Rp612.000,00 per bulan. Kebanyakan tenaga kerja ini memiliki pengalaman kerja di bawah 5 tahun. Pemilik unit usaha, mayoritas adalah perempuan dengan pendidikan terakhir hampir sama banyak antara SD dan SMA/ sederajat. Sebagain besar unit usaha merupakan unit usaha baru yang memulai usaha di bawah 5 tahun.

Faktor-faktor yang mempengaruhi frekuensi kunjungan di Youth Camp secara signifikan adalah jarak tempuh, lama mengetahui keberadaan objek wisata dan umur. Wisata Youth Camp memberi dampak terhadap masyarakat masyarakat sekitar berupa dampak langsung sebesar Rp9.506.000,00 per bulan, dampak tidak langsung sebesar Rp16.123.636,36 per bulan dan dampak lanjutan sebesar Rp10.791.312,53 per bulan. Nilai
Keynesian Income Multiplier pada penelitian ini yaitu sebesar 5,33, nilai Ratio Income Multiplier Tipe 1 sebesar 2,70 dan nilai Ratio Income Multiplier Tipe 2 sebesar 3,83.

\section{DAFTAR PUSTAKA}

Anggraeni AA dan Dritasto A. 2013. Analisis dampak ekonomi wisata bahari terhadap pendapatan masyarakat di Pulau Tidung. Reka Loka, $\mathrm{xx}$ (x): 1-8. https://ejurnal.itenas. ac.id/index.php/rekaloka/article/view/102 [6 Maret 2018].

Fitriani A dan Hidayah N. 2012. Kepekaan humor dengan depresi pada remaja ditinjau dari jenis kelamin. Humanitas, 9 (1): 76-89. http://journal.uad.ac.id/index.php/HUMANIT AS/article/view/351 [7 Maret 2018].

Gujarati DN. 2006. Dasar-dasar Ekonometrik.. Erlangga. Jakarta.

Malantino RA. 2013. Analisis dampak ekonomi obyek wisata terhadap pendapatan masyarakat lokal studi kasus Taman Nasional Bukit Tiga Puluh (TNBT) Kabupaten Indragiri Hulu. Jurnal Ekonomi: 1-17. https://jom.unri.ac.id/ index.php/JOMFEKON/article/view/2707 [6 Maret 2018].

Mutty D. 2015. Analisis dampak ekonomi kegiatan wisata alam (Studi kasus Floating Market Lembang, Bandung). Skripsi. Fakultas Ekonomi dan Manajemen. IPB. Bogor.

Nesparnas [Neraca Satelit Pariwisata Nasional]. 2017. Kontribusi Sektor Pariwisata terhadap PDB Indonesia Tahun 2017. https://www.bps. go.id/publication/download. html. [14 Juli 2019].

Putro P. 2007. Pengelolaan Taman Hutan Raya Wan Abdul Rahman Lampung. ITTO National Workshop Proceedings, 66-77. http://repository.ipb.ac.id/jspui/bitstream/1234 56789/65609/7/4.\%20Prianto\%20Putro.pdf. [27 Oktober 2017].

Ruslan R. 2008. Manajemen Publik Relation dan Media Komunikasi. PT Raja Grafindo Persada. Jakarta.

Winarno GD, Sunarminto T, dan Avenzora R. 2011. Evaluasi potensi ekowisata di Tahura Wan Abdul Rachman Propinsi Lampung. Media Konservasi, 16 (2): 65-72. http://www.neliti.com/id/publications/231337/ evaluasi-potensi-ekowisata-di-tahura-wanabdul.rachman-propinsi-lampung [27 Oktober 2017]. 